\title{
EDUCAÇÃO ESPECIAL E A INCLUSÃO ESCOLAR NO ENSINO SUPERIOR ${ }^{1}$
}

Erica Rodrigues ${ }^{2}$

\begin{abstract}
Resumo: Este estudo teve por objetivo abordar a educação inclusiva no ensino superior, contribuir para a reflexão sobre a educação inclusiva, sobre a legislação brasileira acerca do tema, e, ainda apresentar uma abordagem sobre o histórico da inclusão das pessoas com deficiência na educação e sobre as barreiras no acesso e permanência destes no ensino superior. Metodologicamente o estudo caracterizou-se como descritivo exploratório, e, se apoiou em uma base teórica por meio da pesquisa bibliográfica constituída pela análise de textos publicados na literatura especializada e em periódicos (impressos e/ou disponibilizados na internet). Autores e estudiosos como Aline Maira da Silva, Elsa Midori Shimazaki e João Baptista Cintra Ribas deram suporte aos estudos, e concluiu-se que no Brasil ainda há que se evoluir na inclusão das pessoas com deficiência no ensino superior, pois apesar da previsão legal e das políticas e movimentos de inclusão existentes, há demanda de maior efetividade prática na aplicação de tais leis e ideais, pois além das barreiras físicas (mobiliário inadequado, instalações desprovidas de acessibilidade, etc.) é preciso mudar a cultura organizacional de cada instituição, de modo a promover o acolhimento dos estudantes portadores de necessidades especiais e sua permanência nas instituições de ensino superior.
\end{abstract}

Palavras-chave: inclusão; acessibilidade; pessoa com deficiência.

\section{SPECIAL EDUCATION AND SCHOOL INCLUSION IN HIGHER EDUCATION}

\begin{abstract}
This study aimed to address inclusive education in higher education, contribute to the reflection on inclusive education, on brazilian legislation on the subject, and also to present an approach on the history of inclusion of people with disabilities in education and on the barriers in their access and permanence in higher education. Methodologically, the study was characterized as exploratory descriptive, and, based on a theoretical basis through bibliographic research constituted by the analysis of texts published in specialized literature and in periodicals (printed and / or made available on the internet). Authors and scholars such as Aline Maira da Silva, Elsa Midori Shimazaki and João Baptista Cintra Ribas supported the studies, and concluded that in Brazil there is still a need to evolve in the inclusion of people with disabilities in higher education, because despite the legal provision and of the existing inclusion policies and movements, there is a demand for greater practical effectiveness in the application of such laws and ideals, because in addition to physical barriers (inadequate furniture, facilities without accessibility, etc.) it is necessary to change the organizational culture of each institution, from in order to promote the reception of students with special needs and their permanence in higher education institutions.
\end{abstract}

Key-words: inclusion; accessibility; diseabled person

\section{EDUCACIÓN ESPECIAL E INCLUSIÓN ESCOLAR EN LA EDUCACIÓN SUPERIOR}

Resumen: Este estudio tuvo como objetivo abordar la educación inclusiva en la educación superior, contribuir a la reflexión sobre la educación inclusiva, sobre la legislación brasileña en el tema, y también presentar un enfoque sobre la historia de la inclusión de las personas con discapacidad en la educación y sobre las barreras en su acceso. y permanencia en la educación superior. Metodológicamente, el estudio se caracterizó como exploratorio descriptivo y, con base teórica a través de una investigación bibliográfica constituida por el análisis de textos publicados en literatura especializada y en revistas (impresas y / o disponibles en internet). Autores y académicos como Aline Maira da Silva, Elsa Midori Shimazaki y João Baptista Cintra Ribas apoyaron los estudios y concluyeron que en Brasil aún existe la necesidad de evolucionar en la inclusión de personas con discapacidad en la educación superior, porque a pesar de la disposición legal y de las políticas y movimientos de inclusión existentes, se demanda una mayor efectividad práctica en la aplicación de tales leyes e ideales, pues además de las barreras físicas (mobiliario inadecuado, instalaciones sin accesibilidad, etc.) es necesario cambiar la organización cultura de cada institución, con el fin de promover la recepción de estudiantes con necesidades especiales y su permanencia en las instituciones de educación superior.

Palabras clave: inclusión; accesibilidad; persona discapacitada.

\footnotetext{
${ }^{1}$ Este artigo resulta do trabalho de conclusão de curso apresentado ao curso de Pós Graduação Latu Sensu em Metodologia do Ensino na Educação Superior, ofertado pelo Centro Universitário Internacional - Uninter.

${ }^{2}$ Administradora. Especialista em Metodologia do Ensino na Educação Superior e em Segurança Pública. Mestre em Desenvolvimento Rural Sustentável pela UNIOESTE. E-mail: eriicar@ hotmail.com
} 


\section{Introdução}

A educação inclusiva é um tema atual e de grande relevância no contexto educacional. Em nível global nunca se falou tanto a respeito da busca por um ensino inclusivo e sem preconceitos. No decorrer da história, a deficiência foi objeto de segregação e isolamento, por isso se tem atualmente uma preocupação muito grande em acolher a todos, garantindo uma escola democrática com iguais condições de aprendizagem.

O momento que se vive na educação é de busca pelo reconhecimento dos direitos que têm todos os cidadãos pela igualdade, e, principalmente de busca pela inclusão dos que sofrem algum tipo de preconceito ou são marginalizados em algum sentido no ambiente social, e, destaca-se a relevância da educação inclusiva à pessoa com deficiência.

Este artigo buscou abordar educação inclusiva com especial destaque ao ensino superior, além de contribuir para a reflexão sobre a legislação brasileira acerca do tema, e ainda apresentar uma abordagem sobre o histórico da inclusão das pessoas com deficiência na educação e sobre as barreiras no acesso e permanência destes no ensino superior.

Quanto à garantia dos direitos da pessoa com deficiência, o principal marco de proteção dos direitos humanos desse público em todo o mundo foi publicado pela Organização das Nações Unidas (ONU) em 2006, a Convenção sobre os Direitos das Pessoas com Deficiência. Em 2008, o documento foi adicionado à Constituição federal brasileira, e, ampliou o espaço para o exercício da cidadania de milhares de pessoas no país, a Lei Brasileira de Inclusão trouxe ainda o novo conceito de deficiência, o qual foi apresentado neste estudo.

A necessidade de haver educação para todos, com uma sociedade justa onde a igualdade de direitos prevaleça sem discriminações, possibilitando às pessoas com deficiência a mesma oportunidade que é dada aos demais foram os ideais que inspiraram o desenvolvimento deste artigo. O encaminhamento deste trabalho trilhou a pesquisa bibliográfica. Segundo Bervian (2002), este tipo de pesquisa tem como objetivo de estudo, a consulta e a localização de fontes diversas sobre algum tema que se pretende estudar. A pesquisa bibliográfica procura explicar um problema a partir de referências teóricas publicadas em documentos, e, pode ser realizada independentemente ou como parte de uma pesquisa descritiva e experimental, em ambos os casos, se busca conhecer e analisar as condições culturais do passado ou sobre um determinado assunto, tema ou problema. (BERVIAN 2002)

Por se tratar de uma pesquisa bibliográfica, a coleta de dados neste estudo ocorreu por meio de livros e artigos (impressos e online), atendendo ao objetivo proposto, de abordar a educação inclusiva no ensino superior, contribuir para a reflexão sobre a educação inclusiva, sobre a legislação brasileira acerca do tema, e, ainda apresentar uma abordagem sobre o histórico da inclusão das pessoas com deficiência na educação e sobre as barreiras no acesso e 
permanência destes no ensino superior.

\section{Breve histórico da inclusão da pessoa com deficiência à luz da legislação brasileira}

Até o século XVIII as noções sobre a deficiência eram basicamente ligadas ao misticismo e ocultismo, não havendo base científica para o desenvolvimento de noções do realismo. Segundo Mazzota (2003 p. 16) "O conceito de diferenças individuais não era compreendido ou avaliado. As noções de democracia e igualdade eram ainda meras centelhas na imaginação de alguns indivíduos".

Para Santos (2016), até os anos 1970, o saber médico possuía uma hegemonia para explicar e intervir nas questões relacionadas com as deficiências, a partir de então, houve um deslocamento para os saberes das ciências sociais, estes passaram a compreender a deficiência como um dos aspectos componentes da diversidade humana, cujas atitudes públicas, culturais e institucionais deveriam tratar as demandas das pessoas com deficiência na esfera da promoção da justiça social.

A história mostra que existem pessoas deficientes desde os tempos mais remotos da civilização, mas que em cada tempo a tratativa muda e novos aspectos são considerados na maneira de ver e conviver com os especiais. Neste sentido, três momentos distintos se apresentam na história: pré-história da Educação Especial, a era das instituições e época atual (CARMO, 1991).

$\mathrm{Na}$ antiguidade ou na pré-história da Educação, duas eram as posturas em relação às pessoas doentes, idosas ou deficientes: uma postura era de tolerância; outra, majoritária, optava pela eliminação, menosprezo ou destruição. Esse período é caracterizado pela ignorância e não aceitação do ser deficiente (CARMO, 1991).

Segundo Shimazaki (1993), algumas tribos aceitavam as crianças ou adultos com deficiência, mas acreditavam que os maus espíritos habitavam essas pessoas, e, como a maioria das tribos era nômade acabavam abandonando os idosos, doentes e os deficientes porque essas pessoas geralmente não conseguiam acompanhar o ritmo de caminhadas do grupo.

Outras tribos indígenas eliminavam os recém-nascidos com deficiências e as crianças não desejadas, especialmente as do sexo feminino. Já o povo hebreu acreditava que toda doença crônica ou deficiência simbolizava impureza ou pecado, embora não era comum que se atentasse contra a vida destes. A igreja, no período da Idade Média, condenou o infanticídio, mas ao mesmo tempo acreditava que as anormalidades, eram conferidas por causas sobrenaturais, que as pessoas possuíam poderes especiais, originários do demônio, bruxas e outros espíritos maléficos, por isso precisavam ser exorcizados ou curados (BIANCHETTI, 2000).

Vemos que o infanticídio de pessoas com deficiência era comum entre vários povos na 
antiguidade. Segundo Mantoan (1997) foi o Cristianismo que modificou esta postura diante da pessoa com necessidades especiais, tratando-as como "criaturas de Deus", ele não poderia ser abandonado, já que possui alma. Os portadores de deficiência passam assim a ser assistidos em suas necessidades básicas de alimentação e abrigo, mas não havia a preocupação com seu desenvolvimento e educação.

Com o Renascimento essa fase de ignorância e rejeição da pessoa com deficiência começa a dar espaço para as reflexões sobre direitos e deveres dos deficientes. A partir deste período, segundo Jimenèz (1994) surgem os primeiros interessados em desenvolver estudos sobre as deficiências, e, em paralelo as primeiras instituições com esse fim, tais como a primeira escola pública para surdos em 1755 criada por Charles Michel de l'Epée e um instituto para crianças cegas, criado em Paris por Valentin Haüy em 1784.

Nessa época, pouco tempo depois, aprecem algumas grandes personalidades no campo da cultura, ciência, arte e música que eram deficientes, como Beethoven que ficou surdo, Galileu Galilei que ficou cego, Luís de Camões, que perdeu um de seus olhos em luta, Van Gogh que sofria de depressão e mutilou a própria orelha, entre outros, mas os deficientes continuam até aí discriminados, marginalizados e excluídos da sociedade e da família.

O segundo momento da história da Educação Especial é conhecido por era das instituições, ou fase de segregação institucional, que compreende final do século XVIII e começo do século XIX. É nesse período que a Educação Especial realmente iniciou, quando parte da sociedade admite a necessidade de prestar alguma assistência às pessoas com deficiências. No entanto, nesta fase as pessoas com necessidade especiais são atendidas por instituições cuja filosofia era mais assistencialista, filantrópica e segregacionista, a preocupação era mais assistencial do que educativa, e as medidas assistenciais deste período visavam mais proteger a sociedade destas pessoas do que educá-las e incluí-las (CARMO, 1991).

Mesmo assim é preciso compreender que este período segregativo representou um avanço para a Educação Especial, que, foi beneficiada em alguns aspectos com o desenvolvimento científico e técnico e com a criação de escolas para deficientes na tentativa de encontrar métodos de tratamento. Com ao advento da industrialização, que gerou muitas mudanças sociais e descobertas científicas, surgem alguns esclarecimentos sobre problemas congênitos, disfunções sensoriais e distúrbios mentais e físicos, por fim, com o término da II Guerra Mundial instala-se um campo fértil para discussão dos direitos que garantissem igualdade e fraternidade entre os seres humanos, é o momento que vivemos atualmente.

À luz do século XXI não cabe mais discriminar ou excluir. Atitudes como estas se tornam desajustadas. Porém, é preciso lembrar que foi a partir da reflexão sobre fatos historicamente condenáveis que se percebeu a evolução de conceitos e condutas acerca das pessoas com 
deficiência, ou seja, apesar de bárbaras, foram as atitudes do passado que nos fizeram refletir e buscar novas tratativas, chegando até o momento atual de inclusão e compreensão, onde as escolas públicas buscam atender alunos com deficiências sem distinções, são elaborados documentos que expressam e garantem os direitos humanos e liberdades fundamentais ao portador de deficiência, e, alternativas e modalidades de atendimento ao deficiente que até então seguiam um padrão segregativo e centralizador, pautado na discriminação e exclusão dão espaço aos novos modelos que visam à integração e a inclusão.

No Brasil, o atendimento às pessoas com deficiência teve início na época do Império com a criação de duas instituições: o Instituto dos Meninos Cegos, em 1854, atual Instituto Benjamin Constant - IBC, e o Instituto dos Surdos Mudos, em 1857, atual Instituto Nacional da Educação dos Surdos - INES, ambos no Rio de Janeiro. No início do século XX é fundado o Instituto Pestalozzi - 1926, instituição especializada no atendimento às pessoas com deficiência mental; em 1954 é fundada a primeira Associação de Pais e Amigos dos Excepcionais - APAE e; em 1945, é criado o primeiro atendimento educacional especializado às pessoas com superdotação na Sociedade Pestalozzi (CARMO, 1991).

No decorrer da história é possível perceber que a maior parte das lutas pela efetividade da educação especial, deu-se em âmbito da Educação Básica. A Portaria No 1.793 de 1994, que dispõe sobre a necessidade de complementar os currículos de formação de docentes e outros profissionais que interagem com portadores de necessidades especiais, foi a primeira iniciativa relacionada especificamente ao Ensino Superior, e, esta portaria procura contribuir na formação de professores mais capacitados para atuar nas escolas brasileiras, mas em meio aos movimentos sociais atuais, convém questionar se as instituições de ensino superior estão de fato preparadas para atender ao egresso do ensino escolar fundamental e médio, oferecendo ambientes e profissionais adaptados à realidade atual.

No Brasil a legislação vigente tem conferido ao portador de deficiência maior acesso ao mercado de trabalho, e, o ensino superior é a etapa responsável por capacitar e qualificar os profissionais para o trabalho em todos os níveis da educação e do mercado. Assim, é indispensável que em nível superior haja capacitação e preocupação em receber alunos com alguma deficiência.

O Direito à Educação está expresso na Constituição Federal no artigo 6º, e, a Educação Especial em nosso país vem se estruturando apoiada em decretos leis e pareceres, que vêm avançando com o passar do tempo e abrindo espaço para a inserção do aluno com deficiência. As principais delas, segundo o portal do MEC, são:

A Lei $N^{\circ} 8.859$, de 1994 modifica dispositivos da Lei $n^{\circ} 6.494$, de 1977, estendendo aos alunos de ensino especial o direito à participação em atividades de estágio. 
A Portaria No 1.793 de 1994 - Dispõe sobre a necessidade de complementar os currículos de formação de docentes e outros profissionais que interagem com portadores de necessidades especiais, que, foi a primeira iniciativa do MEC em relação à educação especial em âmbito do ensino superior.

O decreto Lei no 3.298 de 1999, que regulamenta a Lei no 7.853 , de 1989, dispõe sobre a Política Nacional para a Integração da Pessoa Portadora de Deficiência, consolida as normas de proteção, e dá outras providências.

A Portaria No 319 de 1999 - Institui no Ministério da Educação, vinculada à Secretaria de Educação Especial/SEESP a Comissão Brasileira do Braille, de caráter permanente.

A Lei № 10.098, de 2000 - Estabelece normas gerais e critérios básicos para a promoção da acessibilidade das pessoas portadoras de deficiência ou com mobilidade reduzida, e dá outras providências.

A Portaria № 554 de 2000 - Aprova o Regulamento Interno da Comissão Brasileira do Braille. O ensino dessa língua também foi recomendo como disciplina curricular nos cursos de formação de professores e nos cursos de fonoaudiologia.

O Decreto $n^{\circ} 3.956$ de 2001 (Convenção da Guatemala) Promulga a Convenção Interamericana para a eliminação de todas as formas de discriminação contra as Pessoas Portadoras de Deficiência.

A Lei N $\mathrm{N}^{\circ}$ 10.436, de 2002 - Dispõe sobre a Língua Brasileira de Sinais - Libras e dá outras providências.

A Portaria $N^{\circ} 3.284$ de 2003 - Dispõe sobre requisitos de acessibilidade de pessoas portadoras de deficiências, para instruir os processos de autorização e de reconhecimento de cursos, e de credenciamento de instituições.

A Convenção sobre os Direitos das Pessoas com Deficiência aprovada em Assembleia Geral das Nações Unidas em 2006 foi ratificada pelo Brasil em 2008 com status de emenda constitucional, por meio do Decreto 6.949 publicado em 2009.

E por fim, a Lei $N^{\circ} 13.146$ de 2015, que trouxe novidades para a ordem legislativa brasileira, seu principal objetivo foi o de efetivar a inclusão social e a cidadania da pessoa com deficiência com mecanismos legais que visam assegurar e promover de fato o exercício de direitos e liberdades fundamentais, pela pessoa com deficiência em igualdade com as demais pessoas. De acordo com seu art. $1^{\circ}$, a Lei Brasileira de Inclusão da Pessoa com Deficiência (Estatuto da Pessoa com Deficiência), é destinada a assegurar e a promover, em condições de igualdade, o exercício dos direitos e das liberdades fundamentais por pessoa com deficiência, visando à sua inclusão social e cidadania, tendo como base a Convenção sobre os Direitos das Pessoas com Deficiência. 
Ainda assim, o que se pode observar é que praticamente todas as leis, pareceres e decretos, garantem o atendimento educacional especializado a deficientes preferencialmente nas redes regulares de ensino, preservando sempre a continuidade dos serviços educacionais especiais juntamente com o ensino comum, ou se necessário atendimento especial realizado paralelamente. Sua oferta, tanto em quantidade como em qualidade, é, contudo, insuficiente para atender aos seus direitos de acesso e permanência no ensino. O que deve reger o planejamento de políticas públicas de educação "é o compromisso de viabilização de uma educação de qualidade, como direito da população, que impõe aos sistemas escolares a organização de uma diversidade de recursos educacionais." (SOUSA E PRIETO, 2002 p. 124, apud PRIETO; 2003).

\section{Conceito e desafios da pessoa com deficiência}

Segundo a organização Mundial de Saúde - OMS, portadores de deficiência são pessoas que apresentam necessidades próprias e diferentes que requerem atenção específica em virtude de sua condição de deficiência. Genericamente também foram chamados de portadores de necessidades especiais. São pessoas que apresentam significativas diferenças físicas, sensoriais ou intelectuais, decorrentes de fatores inatos ou adquiridos, de caráter permanente, que acarretam dificuldades em sua interação com o meio físico e social.

O conceito mais recente, de acordo com o art. $2^{\circ}$ do Estatuto da Pessoa com Deficiência, considera a pessoa com deficiência aquela que possui impedimento de longo prazo de natureza física, mental, intelectual ou sensorial, o qual, em interação com uma ou mais barreiras, pode obstruir sua participação plena e efetiva na sociedade em igualdade de condições com as demais pessoas (BRASIL, 2015).

No contexto educacional, de acordo com Sassaki (2007), as necessidades especiais mais frequentes nas instituições de ensino referem-se ao Autismo, Transtorno de Déficit de Atenção e Hiperatividade, Síndrome de Down, Dislexia, Disgrafia, Dislalia e a Paralisia.

O autismo é um fenômeno patológico caracterizado pela limitação do desenvolvimento afetivo e social (desligamento do mundo) que na maior parte dos casos é acompanhado de limitação e atraso no desenvolvimento intelectual. Acomete mais as crianças do sexo masculino. Não há padrão de comunicação com outras pessoas, nem afetos.

O transtorno de déficit de atenção e hiperatividade caracteriza os alunos denominados "hiperativos", onde os indivíduos não conseguem concentrar a atenção na situação de aula, ao mesmo tempo em que apresentam uma atividade corporal acima do considerado normal. É passível de tratamento através de medicamentos, antidepressivos e terapia psicológica.

A síndrome de down é consequência de um acidente genético, uma alteração no número de cromossomos. Não é considerada uma doença. Existem três tipos de trissomias, são elas: 
trissomia simples, mosaico e translocação, sendo que, neste último caso, pode se dar por transmissão genética. Os portadores apresentam características fisionômicas peculiares, baixa estatura, como cabelo fino e liso, rosto arrendado, nariz achatado, prega palmar única, mãos pequenas, dedos curtos, pescoço curto e grosso e flacidez muscular. Podem ter desenvolvimento intelectual consideravelmente mais lento que as pessoas comuns, sendo que $95 \%$ dos portadores de Síndrome de Down possuem déficit intelectual.

A dislexia é um distúrbio de aprendizagem especifico da linguagem, caracterizada por dificuldades na decodificação de palavras. Mostra insuficiência no processo fonológico, apresenta sintomas variados, é hereditária e não acompanha, em absoluto, comprometimento da inteligência. A dislexia não é vista como doença e não apresenta comprometimento neurológico.

A disgrafia, distúrbio de aprendizagem semelhante à dislexia, ocasiona dificuldades no desenvolvimento da escrita manual. Os portadores desse distúrbio podem escrever perfeitamente bem com máquinas de escrever ou teclado de computador.

A dislalia, distúrbio da fala, caracterizado pela dificuldade em articular as palavras. Basicamente consiste na má pronúncia das palavras, seja omitindo ou acrescentando fonemas, trocando um fonema por outro ou ainda distorcendo-os. A falha na emissão das palavras pode ainda ocorrer em fonemas ou sílabas. Assim sendo, os sintomas da dislalia consistem em omissão, substituição ou deformação os fonemas $\mathrm{O}$ dislálico pode ter o desenvolvimento da linguagem normal ou levemente retardado. Não se observam transtornos no movimento dos músculos que intervêm na articulação e emissão da palavra.

A Paralisia é um prejuízo permanente do movimento e da postura, resultante de uma desordem encefálica não progressiva (sequela de agressão encefálica). É causada por fatores hereditários ou problemas havidos durante a gravidez, parto, período neonatal ou nos dois primeiros anos de vida. Pode ser acompanhada de rebaixamento mental e distúrbios convulsivos. Pode ser leve (85\% dos casos), moderada (10\%) ou severa (5\%). Na maioria dos casos, os portadores têm plenas condições de frequentar classes regulares em escolas comuns.

Além dos itens citados acima é comum encontrar nos ambientes escolares indivíduos com deficiências múltiplas, ou seja, a ocorrência de duas ou mais deficiências simultaneamente, sejam deficiências intelectuais, físicas ou ambas combinadas.

A educação brasileira sempre se desenvolveu lentamente, ainda há muitas leis por vir, porém, a existência delas muitas vezes não garante sua plena execução, sendo cada vez mais frequente presenciarmos em cenas do cotidiano e até em noticiários da televisão, flagrantes do preconceito, discriminação e não cumprimento de leis. Afinal, para que as leis possam de fato ser colocadas em prática, é necessário que haja a superação de barreiras e preconceitos arraigados. Não é diferente no nível superior. E se falando em educação especial e inclusiva no nível 
superior torna-se ainda mais complexo, pois não se desenvolveu ainda uma prática regulamentada para atender esses educandos.

Segundo a Constituição Federal, Título VIII, artigo 208 e 227, Lei n. 7.853/89. Dispõe sobre o apoio às pessoas com deficiência, sua integração social, assegurando o pleno exercício de seus direitos individuais e sociais (BRASIL, 1989). Vê-se que existe a legislação que ampara a inclusão e o ensino especial, mas instituições com esta identidade de inclusão, ainda são escassas, tanto em estrutura física, quanto em mão de obra qualificada. É necessário haver professores cada vez mais capacitados e especializados para atender esses estudantes.

A conquista da inclusão efetiva e o rompimento das barreiras no acesso e na permanência do aluno especial no ensino é uma realidade que precisa ser alcançada, e que, demanda engajamento das autoridades políticas e também dos envolvidos no processo de socialização do mesmo, desde a família e o próprio indivíduo deficiente, até os gestores das Instituições de Ensino precisam estar dispostos a cumprir com seu papel neste processo, que, visa em sua essência à melhoria e a evolução da sociedade como um todo.

Para que a educação inclusiva seja efetiva é indispensável que este movimento aconteça também no ensino superior. Embora no Brasil ainda não esteja totalmente arraigada a cultura da inclusão social, muitas são as pessoas com deficiência que têm conquistado o acesso ao ensino superior, ainda que não tenham seus direitos totalmente respeitados no que se refere à acessibilidade, à adaptação dos materiais e metodologias, avaliações e principalmente na capacitação dos educadores em trabalhar de forma a eliminar segregações.

Correia (2005) define três parâmetros essenciais da inclusão, e, denomina-os modalidades de atendimento, educação apropriada e serviços adequados, que visam o melhor desenvolvimento do aluno com deficiência em turmas regulares, o que aponta para a necessidade de, no caso dos alunos universitários, haver um conjunto de serviços oferecidos pela universidade.

É preciso perceber que a inclusão não significa apenas matricular o aluno especial em classes de ensino comum ignorando suas necessidades específicas, mas, dando suporte a elas providenciando os recursos necessários para tal, garantindo os direitos dos alunos especiais e, sobretudo o convívio com outros alunos.

De acordo com o IBGE, 23,9\% dos brasileiros tem algum tipo de deficiência, mas diante de um percentual tão significativo, por que ainda consideramos a deficiência uma anormalidade?

Segundo Ribas (1996), a ignorância é a responsável pelos preconceitos relacionados às pessoas que têm deficiências, pois a falta de conhecimento leva ao "achismo", assim, pessoas fazem interpretações que muitas vezes fogem da realidade de vida das pessoas com deficiência física, mental ou sensorial. 
Sobre os preconceitos Ribas (1996, p.64) ainda nos dá a seguinte contribuição:

[...] em maior ou menor grau, todos nós somos preconceituosos. Ninguém escapa. Nem mesmo pesquisadores universitários e acadêmicos. Isso porque a primeira impressão é sempre preconceituosa, já que está relacionada a algo com o qual jamais tivemos contato. É verdade que os pesquisadores universitários e acadêmicos (sobretudo os que trabalham com as ciências humanas) reelaboram o preconceito que existe dentro deles, até mesmo para conseguir pesquisar. E aí, então, conseguem enxergar o que está por trás da primeira imagem (RIBAS, 1996, p.64).

O preconceito com relação a pessoas com deficiência vem muitas vezes imbuído de um sentimento de negação, ou seja, a deficiência é vista apenas como limitação ou como incapacidade. Portanto, apesar do discurso que prega a inclusão social de pessoas com deficiência, ainda não nos acostumamos a olhar os sujeitos que têm deficiência como pessoas comuns, mas às medindo pelo que as falta. Nesta medida, a pessoa com deficiência auditiva é aquela que não ouve, a pessoa com deficiência visual é aquela que não enxerga. Ou seja, nos aproximamos da deficiência a partir da negação. A pessoa com deficiência é sempre aquela que não tem ou não apresenta alguma capacidade que a outra tem ou apresenta. Dessa forma, o sentimento de negação pressupõe sempre uma atitude e um comportamento de negação que, ao longo da história conferiu para essas pessoas sérias consequências como exclusão, marginalização, discriminação, entre outras.

Esse sentimento de negação acompanhado da atitude e do comportamento negativo com relação à pessoa com deficiência acaba por refletir em um sentimento de que é "melhor não viver assim", sentimento esse que ainda é razoavelmente difundido nos dias atuais e que coloca em questão um tema muito polêmico: a morte. Isso porque ao ver a deficiência apenas pelo lado negativo, não se consegue enxergar um horizonte para aquele que tem uma deficiência física, mental ou sensorial, sendo que:

Muitos pais que tiveram filhos com deficiência contam que em algum momento lhes passou pela cabeça que seria melhor, para o próprio filho, não viver. Muitos paraplégicos contam que o desejo de morrer surgiu principalmente logo após o acidente que trouxe a lesão medular. Para os pais que tiveram filhos com deficiência e para as próprias pessoas com deficiência a aceitação passiva da morte resulta da perda de sentido da vida. (RIBAS, 2007, p.24).

Além disso, Ribas (2007) ainda aponta para o perigo de que ao interpretarmos a deficiência como algo suficientemente adversa a ponto de abalar o sentido da vida, logo passemos a justificar a interrupção da gestação de bebês que comprovadamente irão nascer com deficiência, uma vez que o sentimento de que talvez não valha a pena viver sendo uma pessoa 
com deficiência, pode levar à sensação de que talvez não valha a pena nascer com uma deficiência, o que poderia implicar em atitudes como o aborto, por exemplo.

É necessário esclarecermos que o sentimento de que não vale a pena viver tem sua origem nas relações sociais vivenciadas por famílias e por pessoas com deficiência. Estando, portanto, esse sentimento ligado ao sentimento de perda. E essa perda tem sempre como modelo determinado padrão de normalidade. Ter uma deficiência é ter que conviver com a diferença (com toda carga ideológica negativa que esse termo carrega na sociedade). Neste contexto, o sentimento que não vale à pena viver é um produto social que a pessoa com deficiência e seus familiares acabam por consumir em determinado momento da vida. Desta maneira, os sentimentos que prejudicam a vida das pessoas que têm deficiência e de seus familiares são frutos de situações concretas de vida, nas quais estão presentes determinantes sociais, culturais, econômicos e políticos.

Nesta perspectiva, olhar a deficiência a partir da negação resulta, por conseguinte, na negação do direito da pessoa com deficiência de viver na sociedade com igualdade de oportunidades. Sendo assim, a pessoa com deficiência está sujeita na sua vida cotidiana a vários impedimentos. Embora a legislação brasileira refute qualquer tipo de cerceamento no exercício da cidadania dessas pessoas, os impedimentos ainda persistem, se configurando em vários tipos de barreiras. Mas sendo assim, o que é preciso para transformar na prática esta realidade e abrir horizontes a uma nova concepção de vida à pessoa com deficiência?

A integração social é uma realidade da qual não se pode mais fugir, uma alternativa frente à prática de exclusão social a que a pessoa com deficiência viu-se submetida ao longo dos tempos, mas, para que haja verdadeiramente o respeito à pessoa com deficiência, é necessário que a sociedade ofereça possibilidades de desenvolvimento, sendo a participação da sociedade um processo que deve ocorrer simultaneamente aos programas de reabilitação e esforços da pessoa deficiente.

A inclusão social está apoiada no princípio da igualdade, não no sentido de negar as diferenças existentes, mas sim na igualdade de direitos para que as pessoas possam participar da sociedade. Assim, precisamos promover a igualdade apoiando a diversidade, dando chances para que todos possam desenvolver seus potenciais. A inclusão social busca nada menos que a melhora na qualidade de vida da população, pois prima pelos direitos da pessoa com deficiência e pela ruptura das barreiras que existiram até então, libertando não apenas o portador de deficiência, mas também seus familiares, educadores e por fim a sociedade como um todo do juízo de que ser diferente é alguma forma de castigo ou limitação.

Ao termino deste estudo pode-se afirmar que ele atingiu os objetivos a que se propôs, tendo em vista que a pesquisa demonstrou considerações de estudiosos da área sobre o histórico 
da inclusão das pessoas portadoras de necessidades especiais e sobre as barreiras no acesso e permanência destes indivíduos nas instituições de ensino, considerando ainda quais são as principais demandas nas escolas brasileiras e quais as políticas públicas que amparam a pessoa portadora de deficiência em seu ingresso na educação fundamental, media e superior.

\section{Conclusões}

Com a realização do estudo se evidenciou o momento atual da Educação, de inclusão e valorização das diferenças, que a movimentação social é de aceitação e mudança nos comportamentos equivocados do passado, contudo, ainda não são todas as instituições que efetivamente adotam práticas que acolham a pessoa portadora de necessidades especiais, e contribuam com sua permanência nas instituições de ensino superior. É necessário que a legislação ganhe mais efetividade prática, e que as instituições de ensino se adaptem e encontrem meios de adequar não somente suas instalações, mas sua cultura organizacional, pois apesar de haver nos cursos de licenciatura disciplinas com vistas à formação de profissionais capacitados para ensinar e reconhecer as necessidades educacionais específicas de cada aluno, pequeno é o emprego destes profissionais nas próprias instituições de ensino superior.

Cabe ressaltar que a educação inclusiva no ensino superior é direito fundamental, e que compete ao Estado contribuir com medidas que garantam esse direito à pessoa portadora de deficiência. A Lei № 1.793/94, embora preveja o preparo dos futuros profissionais, não supre sozinha a atual demanda dos acadêmicos das IES. Da mesma forma a Lei Brasileira de Inclusão da Pessoa com Deficiência trouxe importantes conceitos sobre acessibilidade, protagonismo e, sobretudo, a ideia de deficiência, ainda assim, as instituições de ensino, precisam buscar antecipar-se à legislação através de ações com vistas a integrar e acolher o indivíduo portador de qualquer deficiência, auxiliando desta forma no ingresso e na permanência destas pessoas no nível superior de ensino.

No século XXI não cabe mais discriminar ou excluir nenhum tipo de diferença, e a partir de fatos historicamente condenáveis, se deu a evolução de conceitos e condutas acerca das pessoas com deficiência até os patamares atuais. Neste momento é importante refletir e compreender as falhas do passado, buscar medidas e ações que excluam as heranças do comportamento equivocado que um dia foi tolerado e adotar práticas inclusivas, seja nas estruturas físicas, na metodologia de ensino e até mesmo na postura individual dos integrantes do ambiente escolar. Não basta que as instituições se adéqüem se não houver uma adequação na postura individual de cada um,

\section{Referências}


BERVIAN, P. A.; CERVO, Amado L.; Roberto da Silva (Orgs) Metodologia Científica. São Paulo: Ed. Pearson Education do Brasil, 2002.

BIANCHETTI, Lucídio. Os trabalhos e os dias dos deuses e dos homens: a mitologia como fonte para refletir sobre normalidade e deficiência. In: Revista Brasileira de Educação Especial, Marília, 2001.

BRASIL. Decreto 3.298/99 de 20/12/1999. Regulamenta a Lei no 7.853, de 24 de outubro de 1989, dispõe sobre a Política Nacional para a Integração da Pessoa Portadora de Deficiência, consolida as normas de proteção. Brasília, 1999.

Decreto 3.956/01 de 08/10/2001. Promulga a Convenção Interamericana para a Eliminação de Todas as Formas de Discriminação contra as Pessoas Portadoras de Deficiência. Brasília, 2001.

Decreto 8.859/94 de 23/03/1994. Modifica dispositivos da Lei ${ }^{\circ} 6.494$, de 7 de dezembro de 1977, estendendo aos alunos de ensino especial o direito à participação em atividades de estágio. Brasília, 1994.

Decreto 11.788/08 de 25/09/2008. Dispõe sobre o estágio de estudantes; altera a redação do art. 428 da Consolidação das Leis do Trabalho - CLT, aprovada pelo Decreto-Lei $\mathrm{n}^{\mathrm{o}}$ 5.452, de $1^{\mathrm{o}}$ de maio de 1943, e a Lei $\mathrm{n}^{\mathrm{o}}$ 9.394, de 20 de dezembro de 1996; revoga as Leis $\mathrm{n}^{\mathrm{os}}$ 6.494, de 7 de dezembro de 1977, e 8.859, de 23 de março de 1994, o parágrafo único do art. 82 da Lei $n^{\circ}$ 9.394, de 20 de dezembro de 1996, e o art. 6º da Medida Provisória $\mathrm{n}^{\mathrm{0}} 2.164-41$, de 24 de agosto de 2001; e dá outras providências. Brasília, 2008.

Decreto 10.098/00 de 27/10/2000. Estabelece normas gerais e critérios básicos para a promoção da acessibilidade das pessoas portadoras de deficiência ou com mobilidade reduzida, e dá outras providências. Brasília, 2000.

Decreto 10.436/02 de 24/04/2002. Dispõe sobre a Língua Brasileira de Sinais - Libras e dá outras providências. Brasília, 2000.

Ministério de Estado da Educação e do Desporto. Recomenda a inclusão de disciplina e conteúdos relativos à normatização e integração da pessoa portadora de deficiência e sugere a expansão de estudos adicionais. Portaria n. 12, de 21 de março de 1996.

Disponível em: <http://portal.mec.gov.br/seesp/arquivos/pdf/port1793.pdf>. Acesso em 23 jun. 2017.

Ministério de Estado de Educação. Institui no Ministério da Educação, vinculada à Secretaria de Educação Especial/SEESP a Comissão Brasileira do Braille, de caráter permanente. Portaria n. 319, de 26 de fevereiro de 1999.

Disponível em: <http://portal.mec.gov.br/seesp/arquivos/pdf/port319.pdf>. Acesso em 23 jun. 2017.

Ministério de Estado de Educação. Aprova o Regulamento Interno da Comissão Brasileira do Braille, na forma do Anexo a esta Portaria. Portaria n. 554, de 26 de abril de 2000. Disponível em: <http://portal.mec.gov.br/seesp/arquivos/pdf/port554.pdf>. Acesso em 23 jun. 2017.

Ministério de Estado de Educação. Dispõe sobre requisitos de acessibilidade de pessoas portadoras de deficiências, para instruir os processos de autorização e de reconhecimento de cursos, e de credenciamento de instituições. Portaria n. 554, de 07 de novembro de 2003. Disponível em: <http://portal.mec.gov.br/seesp/arquivos/pdf/port3284.pdf>. Acesso em 23 jun. 2017. 
Programa de Apoio às Pessoas com Necessidades Especiais. Disponível em: http://www.ppne.unb.br/. Acesso em 23 jun. 2017.

Constituição da República Federativa do Brasil: Promulgada em 05 de outubro de 1988. São Paulo. Ed Saraiva, 1988.

Decreto 7.853/89 de 24/10/1989. Dispõe sobre o apoio às pessoas portadoras de deficiência, sua integração social, sobre a Coordenadoria Nacional para Integração da Pessoa Portadora de Deficiência - Corde, institui a tutela jurisdicional de interesses coletivos ou difusos dessas pessoas, disciplina a atuação do Ministério Público, define crimes, e dá outras providências. Brasília, 1989.

Lei 13.146, de 6 de julho de 2015. Lei Brasileira de Inclusão das Pessoas com Deficiência (Estatuto da Pessoa com Deficiência). Diário Oficial da União 2015, 7 jul 2015.

CARMO, Apolônio Abadio do. Deficiência física: a sociedade brasileira cria, "recupera" e discrimina. Brasília: Secretaria dos Desportos/PR, 1991.

Globo.com-G1. 23,9\% dos brasileiros declaram ter alguma deficiência, diz IBGE. <http://g1.globo.com/brasil/noticia/2012/04/239-dos-brasileiros-declaram-ter-algumadeficiencia-diz-ibge.html>. Acesso em 23 jun. 2017.

JANNUZZI, G. de M. A Educação do Deficiente no Brasil: dos primórdios ao início do século XXI. Campinas: Autores Associados, 2004.

JIMENÈZ, R. B. Necessidades educativas especiais. Lisboa, Dinalivro, 1997.

MANTOAN, Maria Teresa Egler. Compreendendo a deficiência mental: novos caminhos educacionais. São Paulo. Ed. Scipione, 1989.

MAZZOTTA, M. J. S. Educação Especial no Brasil: História e políticas públicas. 5. ed. São Paulo: Cortez, 2005.

MENDES, E. G. A radicalização do debate sobre inclusão escolar no Brasil. Rev. Bras. Educ., Rio de Janeiro, v.11, n.33, 2006, p. 387 -559. Disponível em: <http://www.scielo.br/pdf/rbedu/v11n33/a02v1133.pdf>. Acesso em 23 jun. 2017.

ORGANIZAÇÃO MUNDIAL DA SAÚDE. Classificacion internacional de las deficiencias actividades e participacion: um manual de lãs dimensiones de la inhabilitacion e su funcionamento. Genebra, $1997 . \quad$ Disponível em:,<http://bvsms.saude.gov.br/bvs/publicacoes/politica_nacional_saude_pessoa_deficiencia.p $d f>$. Acesso em 23 jun. 2017.

ORGANIZAÇÃO DAS NAÇÕES UNIDAS. Convenção sobre os Direitos das Pessoas com Deficiência. 2006.

RIBAS, João Baptista Cintra. As pessoas portadoras de deficiência na sociedade brasileira. Brasília, DF: Ed. Corde, 1997.

João Baptista Cintra. Viva a diferença! São Paulo: Ed Moderna, 2006.

SANTOS, Wederson. Deficiência como restrição de participação social: desafios para avaliação a partir da Lei Brasileira de Inclusão. Ciênc. saúde coletiva, Rio de Janeiro, v. 21, n. 10, p. 3007-3015, out. 2016.

SASSAKI, Romeu Kazumi. Inclusão: Construindo uma sociedade para todos. Ed. WVA, 1997.

SHIMAZAKI, Elsa Midori. Fundamentos da Educação Especial. Maringá: 1993 (Palestra na Semana de Pedagogia - UEM)

SILVA, Aline Maira da. Educação Especial e inclusão escolar: história e fundamentos. Ed. Intersaberes, 2014 
SOUSA, Sandra Zákia Lian; PRIETO, Rosângela Gavioli. A educação especial. In: OLIVEIRA, Romualdo Portela; ADRIÃO, Thereza (Orgs.). Organização do ensino no Brasil: níveis e modalidades na Constituição Federal e na LDB. São Paulo, Xamã, 2002.

Recebido em 04/06/2020 - Aprovado em 25/08/2020. 